\title{
Educational Activities of Remote Sensing Archaeology
}

\author{
Diofantos Hadjimitsis ${ }^{a}$ Athos Agapiou ${ }^{a *}$, Vasiliki Lysandrou ${ }^{a}$, Kyriacos \\ Themistocleous ${ }^{a}$, Branka Cuca $^{a}$., Argyro Nisantzi ${ }^{a}$, Rosa Lasaponara ${ }^{b}$, Nicola Masini ${ }^{c}$, \\ Thomas Krauss $^{d}$, Daniele Cerra ${ }^{d}$, Ursula Gessner ${ }^{d}$, Gunter Schreier ${ }^{d}$ \\ ${ }^{a}$ Remote Sensing and Geo-Environment Research Laboratory, Department of Civil Engineering \\ and Geomatics, Cyprus University of Technology, Saripolou str. 2-8, 3036 Limassol, Cyprus; \\ +357 250024 71; d.hadjimitsis@cut.ac.cy; athos.agapiou@cut.ac.cy; \\ vasiliki.lysandrou@cut.ac.cy; k.themistocleous@cut.ac.cy; argyro.nisantzi@cut.ac.cy \\ ${ }^{b}$ National Research Council, Institute of Methodologies for Environmental Analysis, C.da \\ S. Loya, 85050 Tito Scalo, Italy; rosa.lasaponara@imaa.cnr.it \\ ${ }^{c}$ National Research Council, Institute of Archaeological and Monumental Heritage, C.da \\ S. Loya, 85050 Tito Scalo, Italy; n.masini@ibam.cnr.it \\ ${ }^{d}$ DLR - German Aerospace Center, EOC - Earth Observation Center, D-82234 \\ Oberpfaffenhofen,GermanyThomas.Krauss@dlr.de; Daniele.Cerra@dlr.de; \\ ursula.gessner@dlr.de; Gunter.Schreier@dlr.de
}

\begin{abstract}
Remote sensing science is increasingly being used to support archaeological and cultural heritage research in various ways. Satellite sensors either passive or active are currently used in a systematic basis to detect buried archaeological remains and to systematic monitor tangible heritage. In addition, airborne and low altitude systems are being used for documentation purposes. Ground surveys using remote sensing tools such as spectroradiometers and ground penetrating radars can detect variations of vegetation and soil respectively, which are linked to the presence of underground archaeological features.

Education activities and training of remote sensing archaeology to young people is characterized of highly importance. Specific remote sensing tools relevant for archaeological research can be developed including web tools, small libraries, interactive learning games etc. These tools can be then combined and aligned with archaeology and cultural heritage. This can be achieved by presenting historical and pre-historical records, excavated sites or even artifacts under a "remote sensing” approach. Using such non-form educational approach, the students can be involved, ask, read, and seek to learn more about remote sensing and of course to learn about history.

The paper aims to present a modern didactical concept and some examples of practical implementation of remote sensing archaeology in secondary schools in Cyprus. The idea was built upon an ongoing project (ATHENA) focused on the sue of remote sensing for archaeological research in Cyprus. Through H2020 ATHENA project, the Remote Sensing Science and Geo-Environment Research Laboratory at the Cyprus University of Technology (CUT), with the support of the National Research Council of Italy (CNR) and the German Aerospace Centre (DLR) aims to enhance its performance in all these new technologies.
\end{abstract}

Keywords: remote sensing archaeology; education; Cyprus; ATHENA 